\title{
Toward a neural basis for peer-interaction: what makes peer-learning tick?
}

\author{
Ian Clark ${ }^{1}$ and Guillaume Dumas ${ }^{2,3,4}$ \\ ${ }^{1}$ Nagoya University of Commerce and Business, Nagoya, Japan \\ 2 Institut Pasteur, Human Genetics and Cognitive Functions Unit, Paris, France \\ ${ }^{3}$ CNRS UMR3571 Genes, Synapses and Cognition, Institut Pasteur, Paris, France \\ ${ }^{4}$ University Paris Diderot, Sorbonne Paris Cité, Human Genetics and Cognitive Functions, Paris, France
}

\section{Edited by:}

Jesús de la Fuente, University of

Almería, Spain

Reviewed by:

E. Michael Nussbaum, University of

Nevada at Las Vegas, USA

Sung-il Kim, Korea University, South

Korea

*Correspondence:

lan Clark, The Language Centre,

Faculty of Communication, Nagoya

University of Commerce and

Business, 4-4 Sagamine

Komenoki-cho, Nisshin-shi, Aichi

470-0193, Japan

e-mail: clarki@uw.edu
Many of the instructional practices that have been advanced as intrinsically motivating are inherent in socio-constructivist learning environments. There is now emerging scientific evidence to explain why interactive learning environments promote the intrinsic motivation to learn. The "two-body" and "second person" approaches have begun to explore the "dark matter" of social neuroscience: the intra- and inter-individual brain dynamics during social interaction. Moreover, studies indicate that when young learners are given expanded opportunities to actively and equitably participate in collaborative learning activities they experienced feelings of well-being, contentment, or even excitement. Neuroscience starts demonstrating how this naturally rewarding aspect is strongly associated with the implication of the mesolimbic dopaminergic pathway during social interaction. The production of dopamine reinforces the desire to continue the interaction, and heightens feelings of anticipation for future peer-learning activities. Here we review how cooperative learning and problem-solving interactions can bring about the "intrinsic" motivation to learn. Overall, the reported theoretical arguments and neuroscientific results have clear implications for school and organization approaches and support social constructivist perspectives.

Keywords: socio-constructivism, peer-learning, motivation, intersubjectivity, reciprocity, cooperation, reward

\section{INTRODUCTION}

Recent conceptual developments and empirical research undertaken by interdisciplinary research groups (Redcay et al., 2010; Krill and Platek, 2012; Sakaiya et al., 2013; Schilbach et al., 2013) support the proposition that the reward-related networks in the human brain are recruited during cooperative social interaction. This is of particular salience to educators who seek classroom instruction and assessment methods that motivate their students to assist each other (Wood et al., 1976; Vygotsky, 1978), and sustain that assistance until the learning activity has been completed successfully. The relatively recent empirical work by social neuroscientists has helped to elucidate this matter through the use of a technique which records the brain activity of two (or more) individuals simultaneously (Montague et al., 2002; Babiloni et al., 2006). This technique, known as hyperscanning, has proved that brain activity is fundamentally different when we interact with others rather than merely observing them (Dumas et al., 2012a; Guionnet et al., 2012; Schilbach et al., 2006). This supports a common call for taking the role of socialand peer-interaction more seriously as an important driving force behind the construction of the individual motivation to learn in collective settings. Therefore, the central question which guides the construction of this paper is: what is the relationship between "live" social interaction and the reward-related networks of the human brain, which when activated reinforce the motivation to participate in product oriented peer-learning activities.

"Second-person" (Schilbach et al., 2013) and "two-body" (Dumas, 2011; Nadel and Dumas, 2014) approaches argue that the social world and the world of the individual are interdependent, as seen in the foundational work of the influential developmental psychologist Vygotsky $(1978,1987)$, and that of more recent researchers (e.g., Rogoff, 2003). Neuroscience has also shown how motivation can emerge from the social world (Krach, 2010), and how social and reward-processing neural structures relate to each other (Ruff and Fehr, 2014). This article outlines the theoretical conception of an interactive approach to other minds and reviews evidence from neuroimaging, psycho-physiological, and psychological literature to rigorously explore the hypothesis that "intrinsic" motivation is a socially constructed phenomenon. This article reviews the literature on the social construction of motivation and the neuroscientific evidence that supports these perspectives. It discusses the functioning of two human brain networks commonly associated with social interaction, namely the mirror neuron system (MNS) and the "mentalizing" (MENT) system (see Figure 1). While the MNS is especially associated with goal understanding, empathy, and imitation, the MENT system is rather associated with higher-level cognitive processes such as understanding of other's intentions and self-reference (Sperduti et al., 2014). Then, the article presents the concept of "agentic 


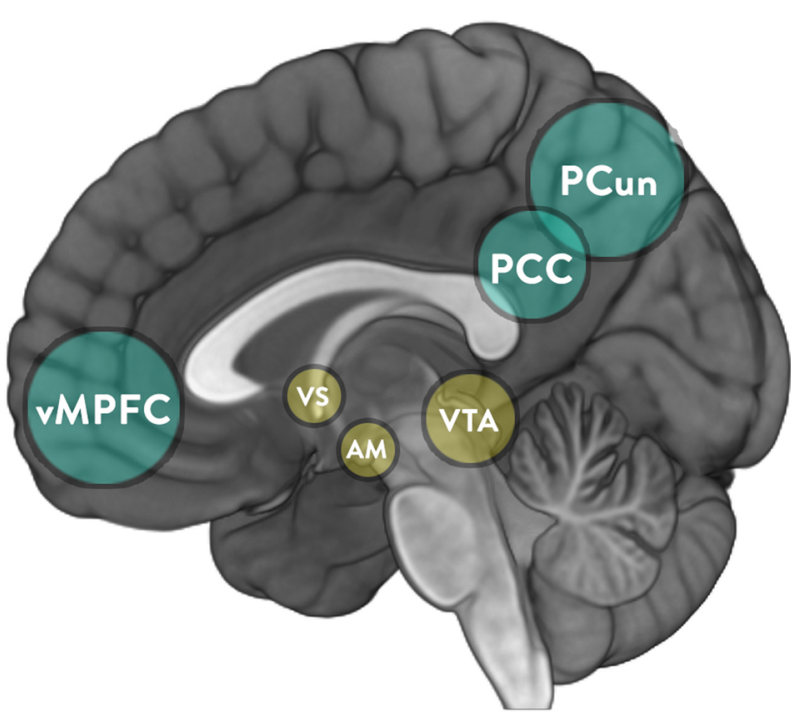

FIGURE 1 | Key brain structures implicated in the MNS (cyan), MENT (red), and mesolimbic reward system (yellow). pIFG, posterior part of the inferior frontal gyrus; alPS, rostral part of the inferior parietal cortex; dPMC, dorsal premotor cortex; M1, primary

equity" and thematic discussions on the role of the mesolimbic reward pathway in cooperative learning, the developmental trajectory of the MENT and what this means for peer-learning. The discussions are focused around Bandura's (2001)"agentic perspective" - a concept which explores the capacity to exercise control over the nature and quality of one's life "within a broad framework of sociostructural influences."

\section{THEORETICAL PERSPECTIVES ON THE SOCIAL CONSTRUCTION OF INTRINSIC MOTIVATION}

Ryan and Deci (2000a) remark, "because intrinsic motivation results in high-quality learning and creativity, it is especially important to detail the factors and forces that engender versus undermine it." When learners are intrinsically motivated they experience a sense of stimulation that compels them to persist with a learning task until its successful completion. Sociocognitive studies on intrinsic motivation take an individualistic perspective, holding that "intrinsic motivation exists in the nexus between a person and a task" (Ryan and Deci, 2000a). Yet, as socio-constructivist theoreticans observe "they have also long recognized that contextual or social factors have a significant influence on these individual processes" (Walker, 2010). Accordingly, the influential socio-cognitive scholar Bandura (1977, p. 227) affirms that "cognitive development, of course is situated in sociocultural practices," declaring such proclamations to be "no longer newsworthy." Similarly, Ryan and Deci (2000b) emphasize the importance of interaction: "social environments can facilitate or forestall intrinsic motivation by supporting versus thwarting people's innate psychological needs." It is clear that socio-cognitive theorists no longer see the realization of instructional and motivational goals as an intra-psychological process unconnected to the social plane. Indeed, students' react strongly to the social environment in schools, reporting emo-

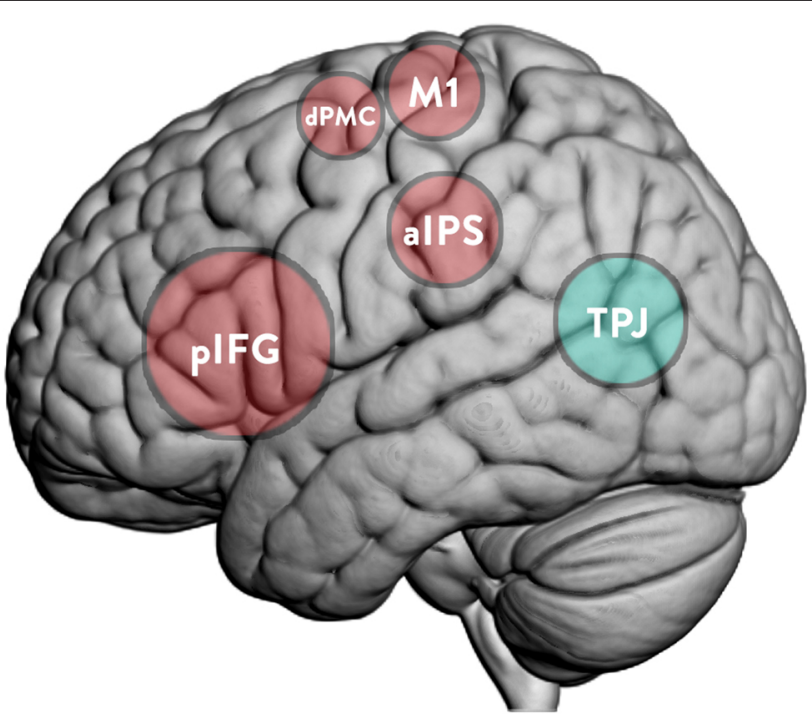

motor cortex; VMPFC, ventromedial part of the prefrontal cortex; PCC, posterior cingulate cortex; PCun, precuneus; TPJ, temporoparietal junction; VS, ventral striatum; VTA, ventral tegmental area; AM, amygdala.

tions that range from apathy to anger (Gilman and Anderman, 2006). It can therefore be no surprise that students rarely report that they find studying to be intrinsically rewarding (Csikszentmihalyi and Larson, 1984).

Even though socio-cognitive theory recognizes the relevance of the social environment, motivation remains an individual phenomenon. More recently, theorists have suggested, after Vygotsky, that motivation is also social in nature (Walker, 2010). Sivan (1986) was the first educational theorist to elaborate on an individualistic theory of motivation. Her ideas received major impetus from Hickey's (1997) article on contemporary socioconstructivist instructional perspectives. Hickey (1997) pointed out that "socio-constructivism is prominent in contemporary educational reform efforts" and urged for the expanded study of "new curricular approaches that follow from this perspective." This has been supported by the recent empirical findings of social neuroscientists on the relationship between social interaction, neural reward (i.e., dopamine production: a hormone and neurotransmitter which plays a major role in reward-motivated behavior) and the motivation to learn (e.g., Redcay et al., 2010; Salamone and Correa, 2012; Sakaiya et al., 2013; Apps and Ramnani, 2014).

Socio-constructivist theoreticians contend that the motivation to learn is a socially constructed phenomenon (Hickey, 1997; Järvelä et al., 2010; Walker, 2010). Unlike their socio-cognitive counterparts, who try to understand the social through its residence in the mind of the individual, socio-constructivist theories give analytical and theoretical primacy to the social world over the individual world (Walker, 2010). In parallel, social neuroscientists argue for the "ontogenetic primacy of social interaction over observation" (Schilbach, 2014). For social constructionists there is a complex bi-directionality between individual learners and their social environment that may be described as a dynamic interde- 
pendence between the social and individual worlds. These worlds are distinguishable so that individual interactants maintain their specific identity, and do not merge into an "undifferentiated matrix" (Coelho and Figueiredo, 2003). Recent empirical findings from social neuroscience indicate that individual motivation and social inter-individual processes complement one another and tend to come into play concurrently (Adolphs, 2009).

From a social constructivist perspective "motivation is a socially negotiated process that results in an observable manifestation of interest and cognitive and affective engagement" (Sivan, 1986). In the specific context of the classroom many foundational studies have explored how social strategies of teachers (Brophy and Kher, 1984) and peers (Peterson et al., 1984) affect the motivation to learn. Thus, the role of social interaction would be emphasized in any discussion on motivation within a social constructivist perspective. Vygotsky's zone of proximal development (ZPD), like Wood et al. (1976) concept of "scaffolding," is a kind of assisted learning and "assisted learning is the method by which instructional and motivational goals are integrated" (Sivan, 1986). If the integration of these goals is to take place teachers, their students, and their peers need to develop intersubjectivity (Walker, 2010)_an interpersonal process that entails the making of subjective inferences in order to gain insights about the intentions and perspectives of others. In this Vygotskian perspective, one can never distinguish between an individual's cognitive ability, the individual's affective state, and the social environment (Rogoff, 1990).

There is compelling evidence that assisted learning holds considerable potential to improve student performance (Mynard and Almarzouqi, 2006; Kayi-Aydar, 2013), ensure outcome equity (Hedin, 1987; Benard, 1989; Reyes and Elias, 2011), enhance instructional efficacy (van Zundert et al., 2010) and, most significantly, motivate students to learn and think together more deeply (Sivan, 1986; Hickey, 1997; Mercer, 2000; Walker, 2010). There is therefore a deepening consensus on the proposition that cooperative "interactive styles" (Black and Wiliam, 2006) of classroom instruction are generally more effective than teacher-fronted didactic methods (Black and Wiliam, 1998; Assessment Reform Group [ARG], 1999; Organization for Economic Cooperation and Development/Centre for Educational Research and Innovation [OECD/CERI], 2005; Nicol and Macfarlane-Dick, 2006; Waxman et al., 2008; Cauley and McMillan, 2010; Clark, 2014).

\section{NEW PERSPECTIVES FROM THE INTERACTIVE TURN OF SOCIAL NEUROSCIENCE}

Schilbach et al. (2013) note, "modern cognitive psychology has retained 'methodological behaviorism' from precisely the psychology it claims to have undermined" (also, Costall, 2006). This points at the enduring tradition of reductionism within social neuroscience, which separates the minds of the interactants from their observable behavior. Consequently, some recent neuroscientific studies (e.g., Gallotti and Frith, 2013) continue to separate neural activity ("social knowing") from the social processes associated with that activity. Such studies focus on the use of, what Becchio et al. (2010) call, "isolation paradigms" in which participants are required to merely observe others, or think about their mental states as a detached observer. This approach highlights the shortcomings of a reductionist approach contend "second person" (Timmermans et al., 2013) and "two-body" (Dumas, 2011; Nadel and Dumas, 2014) neuroscientists. Recent empirical evidence (e.g., Cleeremans, 2011; Timmermans et al., 2012) even support that meta-cognitive skills, such as reflection, are acquired during social interaction. Our brain's biological functions are thus constantly molded by internal reflection and external feedback as we attempt to model (or simulate) other minds during an interaction.

Passive/observational learning entails more limited neural activity than social-interaction (Schilbach et al., 2013). In a socioconstructivist "two-body" or "second-person" perspective interactive learning requires an intricate negotiation between people which recruits the neural processes underlying reciprocal social interaction, and involves both affective and cognitive aspects (Sakaiya et al., 2013). It is through this interaction that students learn to be conscious of their own actions. The resultant metacognitive reflection helps learners to exercise control over their environment as they attempt to realize their personal and learning goals (Bandura, 1997; Clark, 2012). The development of a metacognitive system not only guides the establishment of new behavioral routines, but also help monitoring their quality and progress over time (Chein and Schneider, 2012).

Rewarding social interactions between an individual and the social environment in which they are "embedded" is central to the overall purpose of this review (and will be revisited in a later section on dopaminergic reward). Early studies (Farroni et al., 2002) found that a preference for social engagement emerges as early as $2-5$ days after birth. Even at this age, it is emotionally rewarding for infants to look at faces with eyes looking directly at them. Schilbach et al. (2013) note that when individuals are not emotionally engaged they cannot be expected to gain intersubjectivity - a necessary condition for rewarding peer-learning to occur. Intersubjectivity is the extent to which the "hidden" ideas, intentions and values of one participant are accessible to, understood and reciprocated by the other. A stable inter-subjective state is typically unavailable, so this is a continuous process of observation and inference at the intrapersonal level, and of social negotiation at the interpersonal (Fuchs and de Jaegher, 2010). This continuous process creates the conditions necessary for the integration of motivational and instructional goals (Sivan, 1986), or the "collaborative ZPD [...] best understood as involving mutual adjustment and appropriation of ideas" (Goos et al., 2002; cf. Vygotsky, 1978, 1987).

Damon's (1984) declaration that peer-learning is a "robust phenomena" was made many years prior to the modern neuroimaging procedures available today which have empirically demonstrated why assisted learning motivates people to work and learn together. Yet, even 30 years on, Baines et al. (2007) suggest that peer-learning remains a neglected area by teachers who typically plan for their interactions with students, but not for interactions between and among students. Tiknaz and Sutton (2006) found that peer discussions took place only once or twice in the school year. This was due to time constraints (often cited as a reason; see Organization for Economic Cooperation and Development/Centre for Educational Research and Innovation [OECD/CERI], 2005), complex assessment language, 
and mistrust of students as competent assessors. These teachers are missing the opportunity to motivate their students through expanded opportunities for participation. Social neuroscience suggests a close functional interaction between the social and emotional/motivational systems in the human brain (Lieberman, 2007; Sakaiya et al., 2013). This offers an opportunity for educators to reflect on classroom strategies which capitalize on learners' self-reported preference for cooperative learning activities (Assessment Action Group/AiFL Programme Management Group [AAG/APMG], 2002-2008; Willis, 2010).

\section{THE POSITIVE EMOTIONAL VALENCE OF COOPERATIVE INTERACTION}

The origin of the fundamental human need to belong has been suggested to originate in the advantage of cooperative over individualistic work performance (Baumeister and Leary, 1995; Wagner et al., 2014). The preference for cooperation supports a theory of "emotional-motor resonance" (Preston and de Waal, 2002) that neuroscientists propose as a "phylogenetically early system for empathy" (Molnar-Szakacs and Uddin, 2013). The term "resonance" implies a cognitive tension "between" learners as they seek mutual insights, jointly monitor the interaction and adapt to each other's needs as learners. This shared, and ideally equitable tension, is represented as brains activating in the same areas as they interact (Jackson et al., 2006; Dumas et al., 2012a). Indeed, the intrinsic motivation to cooperate is so pronounced that "when [peers] share visual information in an interpersonal situation, they immediately coordinate their movements even when instructed to be intentionally uncoordinated" (Issartel et al., 2007). Accordingly, Sakaiya et al. (2013) found that: (a) the intensity of emotion associated with reciprocal peer-interaction presents in the mesolimbic dopamine reward system of the brain; and, (b) intersubjectivity is essential. Indeed, without intersubjectivity cooperative human relationships appear impossible (Sakaiya et al., 2013; Schilbach et al., 2013). The quality of intersubjectivity is determined by the predictability and stability of the interaction (Allen and Williams, 2011). Where unpredictability exists the motivation required for effective peerlearning diminishes, and the collaborative ZPD remains inaccessible because learners cannot assist each other until they have mutual insights into each others' intentions and motives.

Learners experience positive feelings in anticipation of mutual interaction (Salamone and Correa, 2012), and of course, during an interaction as learners feel motivated to create and capitalize on opportunities to collaborate together in order to solve a particular problem (Redcay et al., 2010). Moreover, since the reward system also reacts to the value of reward received by others (Apps and Ramnani, 2014), learners can mutually detect and experience others' reward during social interactions thus creating an additional mutual fulfillment during peer-learning. These changes in brain-chemistry are particularly important in motivating young learners to delve more deeply as they think and learn together.

Socio-constructivist theories posit that motivated learners are participants in interactive (Black and Wiliam, 2006; Schilbach, 2014) or cooperative relationships (Storch, 2002; Schilbach et al., 2013). Storch (2002) asserts that a collaborative relation- ship means much more than two or more learners working together. From this perspective cooperation is measured along two dimensions: equality and mutuality. Equality refers to the level of authority or control over the interaction. If learners are to assist each other then they need to demonstrate the ability to take direction from each other equally by a process of interactive turn-taking. Mutuality means the extent of engagement between each other's contributions so that peers who exhibit a high level of mutuality assist each other by sharing ideas and giving feedback. From the realm of social neuroscience, Schilbach et al. (2013) present a similar theoretical model for rewarding and successful peer-assistance. Schilbach employs "emotional engagement" on the horizontal axis and "social interaction" on the vertical axis in parallel to Storch's (2002) preference for "equality" and "mutuality." Storch's (2002) contention that effective thinking and learning is not a matter of people simply working together is consonant with that of Schilbach et al. (2013), who found that "intricate reciprocal reactions" emerge. Reciprocity motivates learners by recruiting the reward circuitry in the human brain, which encourages, sustains, and deepens individual peer-learning. This has been empirically demonstrated by Krill and Platek (2012) during a task requiring the participants to interact cooperatively in order to learn how to negotiate their way through a maze. In support of the long-standing findings of social learning theorists (e.g., Johnson and Johnson, 1996), they concluded that such learning activities "may be more rewarding under conditions of real time cooperation.”

The design and implementation of cooperative learning activities is empirically supported by the interactive, constructive, active, passive (ICAP) theoretical model that differentiates student engagement in learning tasks by categorizing students' learning strategies as Interactive, Constructive, Active, or Passive (Chi, 2009; Menekse et al., 2013). It is founded on theoretical assumptions about how those strategies relate to different cognitive processes. The ICAP hypothesizes that Interactive activities will produce better learning outcomes than Constructive activities, and that all more effective than Passive learning strategies so that $\mathrm{I}>\mathrm{C}>\mathrm{A}>\mathrm{P}$. Interactive (I) engagement entails learning together and is, although not explicitly stated in Chi's work, entirely consonant with social constructivist theory. A Constructive (C) strategy may be self-explaining, or creating a concept map in order to generate new knowledge. Active (A) behaviors include highlighting a textbook chapter and correspond to the internalization of new knowledge. Observational strategies would be considered Passive (P), corresponding to the process of storing knowledge. There is empirical support for the ICAP hypothesis, although the Interactive category carries a caveat (Menekse et al., 2013). That is that engagement should only be considered Interactive, and therefore rewarding, when both individuals in an interaction are being cooperative.

\section{NEURAL GROUNDING OF SOCIAL COGNITION}

The next sections will explore two important neural systems implicated during social- and peer-interaction (see Figure 1). These are, (a) the "MNS"; and, (b) the "MENT system." Research on the latter began as early as 1978 with the seminal work of Premack and Woodruff (1978). The understanding of the 
MNS/MENT relationship, the self, and internal/external stimuli advanced recently (Qin and Northoff, 2011; Sperduti et al., 2014) but require further methodological and theoretical developments (Dumas et al., 2014; Schilbach, 2014). While these systems are connected, they seem to operate at different levels of neural complexity. The MNS regulates low-level simulation processes, or externally focused processes related to one's own or others' visible expressions, actions and emotions. The MENT is involved in higher-level inference-based "MENT" processes, or internally oriented processes, which build a mental-model of others' inner affective and cognitive, states; more clearly understood as an evaluation or reflection function (Uddin et al., 2007). Of course, this separation between MNS and MENT is also linked to a disparity of conceptual and methodological choices in social neuroscience (Schilbach, 2014). Both MNS and MENT are bidirectionally coupled and a full account of social cognition requires integrating both systems in different social context and across development (Dumas et al., 2014).

The MNS and MENT integrate internal and social information to achieve self- and other-understanding (Molnar-Szakacs and Uddin, 2013; Marchetti and Koster, 2014; Sperduti et al., 2014). The coordinated activity of these systems, therefore, provides the neural basis for more effective learning interactions that lead to improvements in meta-cognitive functioning (i.e., reflection). Such improvements are the consequence of the spontaneity inherent to authentic learning interactions which motivate people by activating the reward-related networks (Guionnet et al., 2012) and modifies substrates through neuro-plasticity or molding (Allen and Williams, 2011). Such inter-individual neural molding may explain over time the reinforcing of both anatomical and functional similarity between human brains and thus facilitating our propensity to interact socially with others (Dumas et al., 2012b).

Since MNS and MENT work together to provide a neural basis for social cognition (Sperduti et al., 2014), they pattern our capacity to interact with others and attain personal and learning goals in often challenging social situations (e.g., schools). Recent developments in social neuroscience confirm that mutual social empathy and engagement is a key pre-requisite (e.g., Schilbach et al., 2013) for the kinds of learning interactions that "waken a whole series of functions that are in a stage of maturation lying in the zone of proximal development" (Vygotsky, 1987, p. 212). The MNS and MENT and how they motivate individuals to learn in collective settings is the focus of the subsequent section of this article, beginning with the lower-level simulation processes executed by the MNS.

\section{LOWER-ORDER SOCIAL PROCESSING: THE “MIRROR NEURON SYSTEM"}

The MNS (see Figure 1) is a neural network of "mirror neurons" which responds when we perform an action, and when we see that action being performed by others. The mirror neurons thus tend to be more active during cooperative interactions (NewmanNorlund et al., 2007). During social interaction, the MNS mechanisms unify the sensory perception of an action or emotion and the execution of a (re)action (Sandrone, 2013). More specifically, the MNS detects and monitors the spontaneous and incongruent "affordances" (momentary cues inviting immediate feedback) required for effective peer-interaction to take place (Schilbach et al., 2013).

While the MNS is fundamental for the study of the self in relation to others, and therefore fundamental to social cognition, it is considered a lower-order neural network due to its superficial interpretive function (Sandrone, 2013). The MNS is a conceptually behavioral system in that a literal interpretation would mean that we simply mirror the actions of others (those Newtonian relationships of which reductionists dream). This kind of predictability is evident in machines and simple life forms, but not among humans who live a complex social life (White, 1984; Clark, 2012). The MNS is important in comprehending the intentions of others by processing the sensorimotor or observable actions and emotions of others. It therefore helps people to recognize others as intentional beings; in this case learning-partners (Marchetti and Koster, 2014), and provides the basic platform from which dialogic peer-learning interactions may emerge. Even for young learners of limited social experience the "mirror-like processes" are strongly influenced by complex self-perspectives and experiences, and also by how they perceive the intentions of others (Meltzoff, 2005; Gazzola et al., 2007; Molnar-Szakacs and Uddin, 2013). These findings suggest that the MNS begins construction of the social foundation required for peer-learning (see Cook et al., 2014). It is becoming clear that this construction is a joint process; a fundamentally social process, and a crucial one that sustains cooperative verbal interaction.

The development of social "affordances" (Schilbach et al., 2013 ) into genuine opportunities for learning is dependent on the meta-cognitive awareness of students' and the self-belief that their efforts will result in success (self-efficacy). For each momentary action or emotion we observe, the MNS models or simulates these states internally before preparing and executing a reaction. The MNS is by no means an exclusively visual system, as it responds to other environmental stimulation, e.g., sounds from which humans obtain information about other persons' feelings and intentions (Caetano et al., 2007). As such, when dialog associated with someone else's actions is listened to, the MNS is recruited (Molnar-Szakacs and Uddin, 2013), creating a "neural resonance" during an interaction (Dumas et al., 2010; Marchetti and Koster, 2014). Cooper et al. (2012), for instance, observed that when others are observed receiving a reward the reward centers of the observers' brains are recruited as well (but to a lesser extent of course). Similar phenomena can be observed with empathy: when we observe that others are in physical or emotional pain the observers' brains react as it was experiencing pain as well, running a sort of background simulation (Decety and Lamm, 2009).

The MNS is fundamental to the early development of intersubjectivity. Heyes (2010) and Schilbach et al. (2013) found that the neuro-plasticity of the MNS can be transformed through frequent exposure to the sensorimotor inputs of others. This means that, "the MNS, even in adulthood, can be reconfigured through sensorimotor learning" (Schilbach et al., 2013). So, when learners are mutually engaged on a frequent basis, the simulationroutines of the MNS may improve so they become a more stable basis for the preparation and execution of social and learning 
interactions. The fluid developmental trajectory of the MNS supports the widespread implementation of "relational skills training" (Blatchford et al., 2006), or other socio-emotional strategies (Collaborative for Academic, Social, Emotional Learning [CASEL], 2006) in public schools because they have the potential to support students' identities as successful learners. The "early empathy" made possible by MNS processes is fundamental to the peer-learning relationships which provide the bedrock on which higher-order thinking and learning takes place (Clark, 2012).

\section{HIGHER-ORDER SOCIAL PROCESSING: THE "MENTALIZING" NETWORK}

The MENT of self and others are closely "related processes that are crucial to navigating the social world" (Uddin et al., 2007). The MENT (see Figure 1) integrates internally oriented MNS processes with higher-level subjective inferences (insights) about others in order to prepare and execute appropriate social interactions (Sandrone, 2013). The MENT plays a key role in thinking and learning across the span of learners' lifetimes; from its emergence in 2-day-old newborns (Gao et al., 2009) to its disappearance in brain-dead patients (Boly et al., 2009). While recent studies on the MNS emphasize behavioral responses to social stimulus, the MENT is thought to integrate those lower-order signals with more complex meta-processes (e.g., "reflection-in-action"), which encourage the conscious use of learning strategies related to planning, monitoring, and reflection. Reflective MENT-processes seek to reveal insights into others so that inferences may be made about the other's inner cognitive and affective/motivational states (Shea et al., 2014).

A social-interaction becomes a learning-interaction when the interactants are cognitively and motivationally engaged in peer-learning activities (see Pintrich and Zusho, 2002). During a specifically learning-interaction learners formulate and consciously adapt their social strategies so they maintain intersubjectivity and sustain cooperation (Kirsh and Maglio, 1995; Black and Wiliam, 1998, 2009). It may be seen as a social game, during which the rules become known implicitly through observation and inference, and explicitly through dialog. When learners employ personal and social strategies that influence others they experience rewarding "MENT sensations" related to making progress in the social game (Schilbach et al., 2013). The causal link between peer-learning and positive emotional/motivational states means that interactive styles of learning (Black and Wiliam, 2006) are something to look forward to for students. This is particularly useful in compulsory settings where many students dislike learning (Gilman and Anderman, 2006).

The integration of signals by the MNS and MENT working together in concert is thought to be basis for the internalization of external feedback (Sandrone, 2013). Feedback signals are combined with information from memory in order to select an appropriate and timely response (Molnar-Szakacs and Uddin, 2013). This places beneficial cognitive demands on learners by requiring them to synthesize moment-to-moment feedback with prior knowledge. Synthesis requires employing the important metacognitive process of reflection in order to create new "schematic knowledge" (originated by Bartlett, 1932). Higher-level intersub- jectivity (cognitive empathy) requires reflection on the actions and emotional states of others; including perspective taking and Theory of Mind (ToM; de Waal, 2008). The ToM regions of the human brain are synonymous with the MENT in studies on the neural basis for social interaction. Both terms refer to the substrates recruited when a learner is trying to model the insights of others during an interaction. Advanced meta-cognitive skills, such as reflection, require the recruitment of the higher MENT functions, which, with regular exposure to high-quality cooperative interactions, develop in their neuro-plasticity (Allen and Williams, 2011).

This trajectory toward higher-order social cognition is described by Decety and Jackson (2004) as a process of increasing "cognitive flexibility." The meta-process of reflection, which develops flexibility and is itself elevated by that greater flexibility, is emphasized as pivotal to student achievement (Schön, 1987; Butler and Winne, 1995; Bose and Rengel, 2009; Clark, 2012) and a "key ingredient in the commitment to lifelong learning" (Kuiper and Pesut, 2004). Findings from the educational literature support the proposition that when peer-interaction is emphasized as an instructional strategy, the subsequent activation of the MENT plays a key role in the enhancing student engagement and the acquisition of adaptive thinking and learning strategies (Slavin, 1996; Topping, 1996; Ladyshewsky, 2001; van der Meer, 2011). This indicates that developments in the actual capacity for effective spontaneous thinking or "reflection-in-action" (Schön, 1987) depend on the frequent use of instructional strategies, which expand opportunities for student participation (Clark, 2012). When participation is underpinned by spontaneous (Guionnet et al., 2012) online peer-interaction the experience of learning together stimulates "intrinsically" rewarding MENT activity (Redcay et al., 2010; Sakaiya et al., 2013) which reinforces feelings of anticipation for learning (Salamone and Correa, 2012) and a desire to improve mastery over the rewarding meta-cognitive skills (e.g., reflection) that support achievement.

\section{SOCIAL INTERACTION AND THE REWARD-RELATED NETWORKS OF THE BRAIN}

Reward related signals play a key role in the establishment and maintenance of social relations (Schilbach et al., 2013). Central to social relations is the notion of reciprocity (Melis and Semmann, 2010), which is also intimately connected with high social cognition (Brosnan et al., 2010). Evidence from neuroimaging and psycho-physiological studies has demonstrated "profound differences in neural processing related to the reciprocity of social interaction" (Schilbach et al., 2013). Put another way, cooperative peer-interactions stimulate directly the significant changes in brain chemistry, which influence the quality and duration of the peer-learning activity (Yamasue et al., 2009). This is proposed as a bi-directional relationship so that the positive feelings experienced by learners as they begin an interaction deepens their involvement in social- and peer-interaction which they experience as a rewarding sense of self- and social-awareness with lifelong effects.

Recent research on the production of dopamine by the mesolimbic reward system has exploded the myth that dopamine regulates positive-feelings only when we obtain something that 
satisfies us. Salamone and Correa (2012) found that dopamine neurotransmitters "fire" before we perform an action. The simple expectation of a cooperative interaction, based on past experience, recruits the social reward-networks in the brain. This response makes it much more likely that learners will employ social strategies which sustain the next interaction to a mutually agreeable conclusion. In a carefully structured peer-learning ecology (Clark, 2014), the automatic release of dopamine has a clear potential to reinforce peer-engagement and diminish negative psychological states, caused, for example, by negative public comparison in the classroom. However, Salamone and Correa (2012) emphasize that beneficial outcomes are not inevitable or equally distributed among the participants. The attainment of reciprocal intersubjectivity is facilitated or frustrated by the cultural practices, personal experiences, and current knowledge available to the participants. Public schools should and can organize in ways that reduce these social, cultural (e.g., linguistic) or economic inequities and support marginalized students so they remain persistent (Organization for Economic Cooperation and Development/Centre for Educational Research and Innovation [OECD/CERI], 2011; Putney and Broughton, 2011). When learners (of any age) experience social inequity or psychological threats to their self-esteem (or observe this happening to others), they divert resources away from active participation in the learning process and expend resources on efforts to avoid interaction and withdraw from the situation (Boekaerts and Corno, 2005; Black and Wiliam, 2009).

If students are to actively participate in their own learning progression it is important to help students to acquire positive volitional strategies and reinforce them by providing positive learning experiences (Black and Wiliam, 2009). Classrooms emphasize "respect, responsibility, cooperation, and caring" (Putney and Broughton, 2011) as the guidelines for community conduct; such reciprocal relationships play a key part in any community where the members expect to meet each other regularly (Henrich et al., 2003). In such communities, humans are "conditional cooperators" who discriminately prefer to learn with other cooperators but not with non-cooperators (Sakaiya et al., 2013). It is this preference, described in the next section of this article, which resides at the heart of Bandura's (2001) "agentic" relationship. For peer-learning to flourish, the wider learning environment must be organized in ways which bring about the emotional engagement and interpersonal reciprocity required for social relationships to become learning relationships (Lave and Wenger, 1991; Putney and Broughton, 2011; Clark, 2014).

\section{AGENCY, RECIPROCITY, AND REWARD}

"To be an agent is to intentionally make things happen by one's actions [...]. The core feature of agency enables people to play a part in their self development, adaptation, and selfrenewal with changing times" (Bandura, 2001). Therefore, in a classroom setting agency refers to individual leadership during peer-interaction. When learners are engaged as active participants in cooperative peer-learning tasks they are engaged in a series of neurally rewarding "agentic" interactions. The precise terms of an agentic relationship are negotiated between the participants. This negotiation (or reciprocation) continues for the duration of an interaction, and regulates equality and mutuality (Storch,
2002) among student-peers. When discursive control is equitably circulated every member of the learning community or group has contributed equally and mutually their ideas and opinions are perceived as equally valuable and they should, at least in theory, have experienced equal reward.

However, the search for equity is not the concern of young learners during an interaction. Social neuroscience has discovered that people are very sensitive to the reward they experience when they have influence over an interaction (Fiske and Dépret, 1996; Schilbach et al., 2013). In practice this means that each learner, to some extent, prefers to play the role of influencer or controller because dopamine is released when they are afforded the opportunity to lead the interaction. This requires the cooperation of the other "players" in the social game which is why many social interactions are unrewarding and unpleasant experiences when cooperation is withheld. In social situations where they feel that they are guiding the other they feel valued and the rewardsystems of the brain induce a sense of well-being and self-esteem. Accordingly, in classroom studies conducted by Hedin (1987) it was observed that "the experience of being needed, valued, and respected by another person produced a new view of self as a worthwhile human being." This is agentic equity; a term, which refers to, equally distributed leadership among the interactants. The actual extent of equity between the interactants depends upon interactive turn-taking and the circulation of reciprocal feedback among children. Ideally, everybody will have experienced a sense of self-worth associated with being valued at some point during the interaction.

Learning relationships of this quality do not occur spontaneously. They cannot be attained without: (a) persistent modeling by teachers; (b) frequent opportunities to participate in structured or "scaffolded" peer-learning; or, (c) if required, more prescriptive interventions and training programs which support the socio-emotional needs of learners (Blatchford et al., 2006; Collaborative for Academic, Social, Emotional Learning [CASEL], 2006). They take turns in a way known as the "interactive turn" by directing each other in accordance with Storch's (2002) notion of equality as a necessary aspect of the privileged learning "contract" between them. The ventral striatum (VS; see Figure 1) in the midbrain (MENT regions) and other reward processing structures are furthermore recruited during cooperative (Schilbach et al., 2013) and spontaneous (Guionnet et al., 2012) interaction.

\section{THE DOPAMINERGIC PATHWAY IN SOCIAL REWARD}

Recent evidences have emerged that cooperative peer-interaction recruits the mesolimbic dopamine reward system in the human brain, providing a feeling of fulfillment to the learners engaged in the interaction (Redcay et al., 2010; Krill and Platek, 2012; Sakaiya et al., 2013; Pfeiffer et al., 2014). The VS is particularly important in the dopaminergic pathway (see Figure 1). It receives rich dopaminergic input from the midbrain (Tabibnia and Lieberman, 2007) and integrates actions with reward, thus capable of translating social information into coding of new behavior, including learning (Báez-Mendoza and Schultz, 2013). Cooperative and shared social context seems to particularly activate the VS (Tabibnia and Lieberman, 2007; Fareri et al., 2012; Guionnet et al., 2012); Schilbach et al. (2010) even mention 
a "VS effect" that was triangulated by questionnaire responses and which confirmed that cooperative social interaction "was experienced as more pleasant and less effortful" than doing the opposite of their partner. The amygdala also plays a key role in reward-processing activity (Baxter and Murray, 2002) and use of reward to motivate the use of social learning strategies (Murray, 2007).

Developments in functional magnetic resonance imagining (fMRI) elucidate on the connection between reciprocal peerinteraction and the amygdala, which coordinates with other reward related structures; including the ventral tegmental area (VTA). For example, Sakaiya et al. (2013) found a link between amygdala activity and the cooperative learning interactions, which regulate agentic equity. Amygdala activation was greater for cooperative social strategies than for interactions, which the interactants perceived as unpredictable. When the participants in Sakaiya et al. (2013) study were exposed to unstable interaction strategies, when reciprocation and non-reciprocation could not be predicted, they reported a corresponding loss of insight into their partner's intentions. The consequence of this lack of mutual empathy was a diminished desire to continue the learning interaction. Consequently, learning ceases along with the motivation to do so. This was confirmed by interviews in which the participants in Sakaiya et al.'s (2013) study expressed a preference for changing partners or discontinuing the interaction entirely.

Reciprocity, mutuality, and shared intention are key components for an efficient co-regulation of spontaneous social interaction (Nadel and Dumas, 2014). Cooperative interactions are especially of this kind and rewarding experiences usually emerge between two or more intentionally supportive peers (cf. Vygotsky, 1978, 1987). When interactants use cooperative social strategies, brain structures associated with the dopaminergic reward system are indeed more active (Redcay et al., 2010; Krill and Platek, 2012; Sakaiya et al., 2013; Schilbach et al., 2013); The same effect is observed for the anticipation of an interaction (Salamone and Correa, 2012), when interactants develop a common understanding in regard to motive and the goals and the pay off so that all participants achieve the same goal successfully (Rilling et al., 2002; Decety et al., 2004). In all those cases, dopamine thus creates and sustains the positive emotional states during social interaction and, in the case of learning, contributes to the intrinsic motivation of learners.

\section{THE DEVELOPMENTAL TRAJECTORY OF THE MENT AND PEER-LEARNING}

Interactive peer-dialog, characteristic of learners who are able to employ "reflection-in-action," is founded upon the level of "spontaneous activity" (Fair et al., 2008) taking place across the MENT regions of the human brain. Fair et al. (2008) posit that more mature MENT substrates exhibit a higher level of spontaneity in response to social affordances. Some studies suggest that the MENT's maturity is connected to the chronological age of the learner. For example, Bahrami et al. (2010) emphasize the finding that enhancements in the reflective and introspective aspects of social cognition accrue throughout learners' lives.

When investigating the earliest years of cognitive development, Fransson et al. (2008) could not detect a complete MENT system in the infants in their study. This finding was elaborated on by the pioneering work of Fair et al. (2008) who found the MENT to be only "sparsely functionally connected" at 7-9 years of age. The same study emphasized a growth-trajectory of the MENT, suggesting, "over development, these regions integrate into a cohesive, interconnected network." In a later study, Washington et al. (2014) also investigated the structural connectivity between the MENT sub-structures. Like Fair et al. (2008), they found weak structural connectivity in 7-9 year olds, so that these regions of the brain still did coordinate efficiently. Further, Washington et al. (2014) discovered that the MENT regions of the brain do not begin to work together in concert (as they do in adults) until ages 11-13. Despite these structural weaknesses across the MENT regions in pre-teens and children of elementary school age, learners as young as 8 years can routinely recall and restructure (i.e., reflection) the content of past and present thinking and learning (Fair et al., 2008).

The foundational work of Fair et al. (2008) supports the conclusion that the MENT is a relatively functional structure at the age when meta-cognitive skills (i.e., reflection) become developed. Supekar et al. (2010) conducted a similar study to confirm the earlier study conducted by Fair et al. (2008). Supekar et al. (2010) found that by the age of 8 , some connections between MENT substrates were mature and others were in an earlier state of maturation (cf. Vygotsky, 1978, 1987). In accordance with the earlier study by Fair et al. (2008), Supekar et al. (2010) found that despite sparse functional connectivity, 8-year-old children can reach "adult-like levels" in sub-structures implicated in social cognition. Those results follow a more general trend of brain networks that mature from a "local" organization to a "distributed" organization (Fair et al., 2009). Overall, these emerging findings indicate that children should be meaningfully assessed for their ability to establish agentic equity at around the age of 8 years old; an age at which peer-learning may begin to become an effective instructional strategy. On this latter point, the early activation of the dopaminergic reward linked with social interaction encourages peer-learning partnerships, which Reyes and Elias (2011) found to establish "the most powerful integration of protective processes"; processes, which protect young learners from academic disaffection and failure later in life.

\section{CONCLUSION}

Johnson and Johnson (1983) emphasize that,

\begin{abstract}
"[...] there is no type of task on which cooperative efforts are less effective than are competitive or individualistic efforts, on most tasks[...]concept attainment, verbal problem-solving, categorization, spatial problem-solving, retention and memory, motor, guessing-judging-predicting, cooperative efforts are more effective in promoting achievement."
\end{abstract}

Scientific evidence indicates that effective peer interactions are characterized as stable, equitable, mutually engaging and reciprocal interactions. Cooperative social interaction depends upon the establishment and maintenance of intersubjectivity; a persistent process that sustains any learning-interaction for its entire duration. When learners work together cooperatively they rely on the moment-to-moment integration of lower-order motor 
cues in the MNS and higher-order reflection and projection processes in the MENT regions of the human brain. Redcay et al. (2010) found that those key neural structures recruited for everyday social interaction (right temporo-parietal junction, anterior cingulate cortex, and right superior temporal sulcus) are "consistently linked" to the activation of the dopaminergic reward system (amygdala and VS; see Figure 1). The same study emphasized "the powerful and pervasive drive" for humans to seek out social interactions, and reiterated that contingent interactions with another person recruits the reward systems (Guionnet et al., 2012; Krill and Platek, 2012; Sakaiya et al., 2013; Schilbach et al., 2013).

Cooperative peer-learning can be described as the instructional use of pairs or small groups so that students work together to maximize their own and each other's learning. It may be contrasted with competitive contexts and individualistic contexts (Johnson, 2009). Significantly, socio-constructivist contexts which promote an interactive style of knowledge construction sustain and deepen participation (cf. Lave and Wenger, 1991) between learners, and provide dopaminergic reward in anticipation of (Salamone and Correa, 2012) and during the learninginteraction (Redcay et al., 2010; Guionnet et al., 2012; Krill and Platek, 2012; Sakaiya et al., 2013; Schilbach et al., 2013), which cease after the interaction has ended. These emerging findings from within social neuroscience inform our understanding of the value of peer-learning in classrooms across multiple contexts. The opportunities for future research into the "dark matter" of social neuroscience are potentially vast in their scope and implication. A current finding of general relevance is that the brain responds differently depending on whether learning entails passive observation or active participation (Schilbach, 2014). Both learning "stances" involve intricate processes of internalization, reflection, and social knowledge construction, which together promote the intrinsic motivation required for successful outcomes in public schools.

\section{REFERENCES}

Adolphs, R. (2009). The social brain: neural basis of social knowledge. Annu. Rev. Psychol. 60, 693-716. doi: 10.1146/annurev.psych.60.110707.163514

Allen, M., and Williams, G. (2011). Consciousness, plasticity, and connectomics: the role of intersubjectivity in human cognition. Front. Psychol. 2:20. doi: 10.3389/fpsyg.2011.00020

Apps, M. A., and Ramnani, N. (2014). The anterior cingulate gyrus signals the net value of others' rewards. J. Neurosci. 34, 6190-6200. doi: 10.1523/ JNEUROSCI.2701-13.2014

Assessment Action Group/AiFL Programme Management Group (AAG/APMG). (2002-2008). AifL-Assessment is for Learning. Available at: http://www. ltscotland.org.uk/assess [accessed March 14, 2008].

Assessment Reform Group (ARG). (1999). Assessment for Learning: Beyond the Black Box. Cambridge: Cambridge University, School of Education.

Babiloni, F., Cincotti, F., Mattia, D., Mattiocco, M., De Vico Fallani, F., Tocci, A., et al. (2006). Hypermethods for EEG Hyperscanning. Conf. Proc. IEEE Eng. Med. Biol. Soc. 1, 3666-3669. doi: 10.1109/IEMBS.2006.260754

Báez-Mendoza, R., and Schultz, W. (2013). The role of the striatum in social behavior. Front. Neurosci. 7:233. doi: 10.3389/fnins.2013.00233

Bahrami, B., Olsen, K., Latham, P. E., Roepstorff, A., Rees, G., and Frith, C. D. (2010). Optimally interacting minds. Science 329, 1081-1085. doi: 10.1126/science. 1185718

Baines, E., Blatchford, P., and Chowne, A. (2007). Improving the effectiveness of collaborative group work in primary schools: effects on science attainment. $\mathrm{Br}$. Educ. Res. J. 33, 663-680. doi: 10.1080/01411920701582231
Bandura, A. (1977). Social Learning Theory. Englewood Cliffs, NJ: Prentice Hall.

Bandura, A. (1997). Self-Efficacy: The Exercise of Control. New York, NY: Freeman.

Bandura, A. (2001). Social cognitive theory: an agentic perspective. Annu. Rev. Psychol. 2, 1-26. doi: 10.1146/annurev.psych.52.1.1

Bartlett, F. C. (1932). Remembering: A Study in Experimental and Social Psychology. Cambridge: Cambridge University Press.

Baumeister, R., and Leary, M. (1995). The need to belong: desire for interpersonal attachments as a fundamental human motivation. Psychol. Bull. 117, 497-529. doi: 10.1037/0033-2909.117.3.497

Baxter, M., and Murray, E. (2002). The amygdala and reward. Nat. Rev. Neurosci. 3, 563-573. doi: 10.1038/nrn875

Becchio, C., Sartori, L., and Castiello, U. (2010). Toward you: the social side of actions. Curr. Direct. Psychol. Sci. 19, 183-88. doi: 10.1177/0963721410370131

Benard, B. (1989). Towards family. Prev. Forum 9, 7-14.

Black, P., and Wiliam, D. (1998). Inside the black box: raising standards through classroom assessment. Phi Delta Kappa. 80, 139-148.

Black, P., and Wiliam, D. (2006). "Assessment for learning in the classroom," in Assessment and Learning, ed. J. Gardner (London: Sage), 9-25.

Black, P., and Wiliam, D. (2009). Developing the theory of formative assessment. Educ. Assess. Eval. Account. 21, 5-31. doi: 10.1007/s11092-008-9068-5

Blatchford, P., Baines, E., Rubie-Davies, C., Bassett, P., and Chowne, A. (2006). The effect of a new approach to group-work on pupil-pupil and teacherpupil interactions. J. Educ. Psychol. 98, 750-765. doi: 10.1037/0022-0663.98. 4.750

Boekaerts, M., and Corno, L. (2005). Self-regulation in the classroom: a perspective on assessment and intervention. Appl. Psychol. Int. Rev. 54, 199-231. doi: 10.1111/j.1464-0597.2005.00205.x

Boly, M., Tshibanda, L., Vanhaudenhuyse, A., Noirhomme, Q., Schnakers, C., and Ledoux, D. (2009). Functional connectivity in the default network during resting state is preserved in a vegetative but not in a brain dead patient. Hum. Brain Mapp. 30, 2393-2400. doi: 10.1002/hbm.20672

Bose, J., and Rengel, Z. (2009). A model formative assessment strategy to promote student- centered self-regulated learning in higher education. US-China Educ. Rev. 6, 29-35.

Brophy, J., and Kher, N. (1984). Teacher Socialization as a Mechanism for Developing Student Motivation to Learn. East Lansing, MI: Michigan State University, Institute for Research on Teaching.

Brosnan, S. F., Salwiczek, L., and Bshary, R. (2010). The interplay of cognition and cooperation. Philos. Trans. R. Soc. Lond. B Biol. Sci. 365, 2699-2710. doi: 10.1098/rstb.2010.0154

Butler, D. L., and Winne, P. H. (1995). Feedback and self-regulated learning: a theoretical synthesis. Rev. Educ. Res. 65, 245-281. doi: 10.3102/00346543065003245

Caetano, G., Jousmäki, V., and Hari, R. (2007). Actors and observers primary motor cortices stabilize similarly after seen or heard motor actions. Proc. Natl. Acad. Sci. U.S.A. 104, 9058-9062. doi: 10.1073/pnas.0702453104

Cauley, M. C., and McMillan, J. H. (2010). FA techniques to support student motivation and achievement. Clear. House 83, 1-6. doi: 10.1080/00098650903267784

Chein, J. M., and Schneider, W. (2012). The brain's learning and control architecture. Curr. Dir. Psychol. Sci. 21, 78-84. doi: 10.1177/0963721411434977

Chi, M. (2009). Active-constructive-interactive: a conceptual framework of differentiating learning activities. Top. Cogn. Sci. 1, 73-105. doi: 10.1111/j.17568765.2008.01005.x

Clark, I. (2012). Formative assessment: assessment is for self-regulated learning. Educ. Psychol. Rev. 24, 205-249. doi: 10.1007/s10648-011-9191-6

Clark, I. (2014). Equitable learning outcomes: supporting economically and culturally disadvantaged students in 'Formative Learning Environments'. Improv. Sch. 17, 1-27. doi: 10.1177/1365480213519182

Cleeremans, A. (2011). The radical plasticity thesis: how the brain learns to be conscious. Front. Psychol. 2:86. doi: 10.3389/fpsyg.2011.00086

Coelho, N., and Figueiredo, L. (2003). Patterns of intersubjectivity in the constitution of subjectivity: dimensions of otherness. Cult. Psychol. 9, 193-208. doi: 10.1177/1354067x030093002

Collaborative for Academic, Social, Emotional Learning (CASEL). (2006). What is SEL? The Collaborative for Academic, Social, and Emotional Learning (CASEL). Available at: http://www.casel.org/aboutsel/WhatisSEL.php [accessed November 23, 2011].

Cook, R., Bird, G., Catmur, C., Press, C., and Heyes, C. (2014). Mirror neurons: from origin to function. Behav. Brain Sci. 37, 177-192. doi: 10.1017/ S0140525X13000903 
Cooper, J. C., Dunne, S., Furey, T., and O’Doherty, J. P. (2012). Human dorsal striatum encodes prediction errors during observational learning of instrumental actions. J. Cogn. Neurosci. 24, 106-118. doi: 10.1162/jocn_a_00114

Costall, A. (2006). Introspectionism and the mythical origins of modern scientific psychology. Conscious. Cogn. 15, 634-654. doi: 10.1016/j.concog.2006. 09.008

Csikszentmihalyi, M., and Larson, R. (1984). Being Adolescent: Conflict and Growth in the Teenage Years. New York: Basic Books.

de Waal, F. B. M. (2008). Putting the altruism back into altruism: the evolution of empathy. Annu. Rev. Psychol. 59, 279-300. doi: 10.1146/annurev.psych. 59.103006.093625

Damon, W. (1984). Peer education the untapped potential. J. Appl. Dev. Psychol. 5, 331-343. doi: 10.1016/0193-3973(84)90006-6

Decety, J., and Jackson, P. L. (2004). The functional architecture of human empathy. Behav. Cogn. Neurosci. Rev. 3, 71-100. doi: 10.1177/1534582304267187

Decety, J., Jackson, P. L., Sommerville, J. A., Chaminade, T., and Meltzoff, A. N. (2004). The neural bases of cooperation and competition: an fMRI investigation. Neuroimage 23, 744-751. doi: 10.1016/j.neuroimage.2004.05.025

Decety, J., and Lamm, C. (2009). "The biological basis of empathy" in Handbook of Neuroscience for the Behavioral Sciences, eds J. T. Cacoppo and G. G. Berntson (New York: John Wiley and Sons), 940-957.

Dumas, G. (2011). Towards a two-body neuroscience. Commun. Integr. Biol. 4, 349 352. doi: $10.4161 /$ cib.4.3.15110

Dumas, G., Kelso, J., and Nadel, J. (2014). Tackling the social cognition paradox through multi-scale approaches. Front. Psychol. 5:882. doi: 10.3389/ fpsyg.2014.00882

Dumas, G., Martinerie, J., Soussignan, R., and Nadel, J. (2012a). Does the brain know who is at the origin of what in an imitative interaction? Front. Hum. Neurosci. 6:128. doi: 10.3389/fnhum.2012.00128

Dumas, G., Chavez, M., Nadel, J., and Martinerie, J. (2012b). Anatomical connectivity influences both intra- and inter-brain synchronization. PLoS ONE 7:e36414. doi: 10.1371/journal.pone.0036414

Dumas, G., Nadel, J., Soussignon, R., Martinerie, J., and Garnero, L. (2010). Inter-brain synchronization during social interaction. PLOS ONE 5:e12166. doi: 10.1371/journal.pone.0012166

Fair, D. A., Cohen, A. L., Dosenbach, N., Church, J., Miezin, F., Deanna, M., et al. (2008). The maturing architecture of the brain's default network. Proc. Natl. Acad. Sci. U.S.A. 105, 4028-4032. doi: 10.1073/pnas.0800376105

Fair, D. A., Cohen, A. L., Power, J. D., Dosenbach, N. U., Church, J. A., Miezin, F. M., et al. (2009). Functional brain networks develop from a "local to distributed" organization. PLoS Comput. Biol. 5:e1000381. doi: 10.1371/journal.pcbi.1000381

Fareri, D. S., Niznikiewicz, M. A., Lee, V. K., and Delgado, M. R. (2012). Social network modulation of reward-related signals. J. Neurosci. 32, 9045-9052. doi: 10.1523/jneurosci.0610-12.2012

Farroni, T., Csibra, G., Johnson, M., and Simion, F. (2002). Eye contact detection at birth. Proc. Natl. Acad. Sci. U.S.A. 99, 9602-9605. doi: 10.1073/pnas. 152159999

Fiske, S. T., and Dépret, E. (1996). Control, interdependence, and power: understanding social cognition in its social context. Eur. Rev. Soc. Psychol. 7, 31-61. doi: 10.1080/14792779443000094

Fransson, P., Skiöld, B., Horsch, S., Nordell, A., Blennow, M., Lagercrantz, H., et al. (2008). Resting state networks in the infant brain. Proc. Natl. Acad. Sci. U.S.A. 104, 15531-15536. doi: 10.1073/pnas.0704380104

Fuchs, T., and de Jaegher, H. (2010). Enactive intersubjectivity: participatory sensemaking and mutual incorporation. Phenomenol. Cogn. Sci. 8, 465-486. doi: 10.1007/s11097-009-9136-4

Gallotti, M., and Frith, C. D. (2013). Social cognition in the we-mode. Trends Cogn. Sci. 17, 160-165. doi: 10.1016/j.tics.2013.02.002

Gao, W., Zhu, H., Giovanello, K. S., Smith, J. K., Shen, D., and Gilmore, J. H. (2009). Evidence on the emergence of the brain's default network from 2-week-old to 2year-old healthy pediatric subjects. Proc. Natl. Acad. Sci. U.S.A. 106, 6790-6795. doi: 10.1073/pnas.0811221106

Gazzola, V., van der Worp, H., Mulder, T., Wicker, B., Rizzolatti, G., and Keysers, C. (2007). Aplasics born without hands mirror the goal of hand actions with their feet. Curr. Biol. 17, 1235-1240. doi: 10.1016/j.cub.2007.06.045

Gilman, R., and Anderman, E. (2006). Motivation and its relevance to school psychology: an introduction to the special issue. J. Sch. Psychol. 44, 325-329. doi: 10.1016/j.jsp.2006.04.006
Goos, M., Galbraith, P., and Renshaw, P. (2002). Socially mediated meta-cognition: creating collaborative zones of proximal development in small group problem solving. Educ. Stud. Math. 49, 192-223. doi: 10.1023/A:1016209010120

Guionnet, S., Nadel, J., Bertasi, E., Sperduti, M., Delaveau, P., and Fossati, P. (2012). Reciprocal imitation: toward a neural basis of social interaction. Cereb. Cortex 22, 971-978. doi: 10.1093/cercor/bhr177

Hedin, D. (1987). Students as teachers: a tool for improving school climate and productivity. Soc. Policy 17, 42-47.

Henrich, J., Bowles, S., Boyd, R., Hopfensitz, A., Richardson, P., and Sigmund, K. (2003). "The cultural and genetic evolution of human cooperation" in Generic and Cultural Evolution of Cooperation, ed. P. Hammerstein (Cambridge: MIT Press), 445-468.

Heyes, C. (2010). Where do mirror neurons come from? Neurosci. Biobehav. Rev. 34, 575-583. doi: 10.1016/j.neubiorev.2009.11.007

Hickey, D. (1997). Motivation and contemporary socio-constructivist instructional perspectives. Educ. Psychol. 32, 175-193. doi: 10.1207/s15326985ep3203_3

Issartel, J., Marin, L., and Cadopi, M. (2007). Unintended interpersonal coordination: "Can we march to the beat of our own drum?" Neurosci. Lett. 411, 174-179. doi: 10.1016/j.neulet.2006.09.086

Jackson, P., Brunet, E., Meltzoff, A., and Decety, J. (2006). Empathy examined through the neural mechanisms involved in imagining how I feel versus how you feel pain. Neuropsychologia 44, 752-761. doi: 10.1016/j.neuropsychologia. 2005.07.015

Järvelä, S., Volet, S., and Järvenoja, H. (2010). Research on motivation in collaborative learning: moving beyond the cognitive-situative divide and combining individual and social processes. Educ. Psychol. 45, 15-27. doi: 10.1080/ 00461520903433539

Johnson, D. W. (2009). Reaching Out: Effectiveness and Self-Actualization. Boston: Allyn \& Bacon.

Johnson, D. W., and Johnson, R. T. (1983). "The socialization and achievement crises: are cooperative learning experiences the solution?" in Applied Social Psychology Annual 4, ed. L. Bickman (New York: Sage Publications), 119-164.

Johnson, D. W., and Johnson, R. T. (1996). "The role of the cooperative learning in assessing and communicating student learning" in 1996 ASCD Yearbook: Communicating Student Learning, ed. T. R. Gusky (Alexandria: Association for Supervision and Curriculum Development), 25-46.

Kayi-Aydar, H. (2013). Scaffolding language learning in an academic ESL classroom. ELT J. 67, 324-335. doi: 10.1093/elt/cct016

Kirsh, D., and Maglio, P. (1995). On distinguishing epistemic from pragmatic action. Cogn. Sci. 18, 513-549. doi: 10.1207/s15516709cog1804_1

Krach, S. (2010). The rewarding nature of social interactions. Front. Behav. Neurosci. 4:22. doi: 10.3389/fnbeh.2010.00022

Krill, A. L., and Platek, S. M. (2012). Working together may be better: activation of reward centers during a cooperative maze task. PLoS ONE 2:e30613. doi: 10.1371/journal.pone.0030613.t002

Kuiper, R. A., and Pesut, D. J. (2004). Promoting cognitive and meta-cognitive reflection reasoning skills in nursing practice: self-regulated learning theory. J. Adv. Nurs. 45, 381-391. doi: 10.1046/j.1365-2648.2003.02921.x

Ladyshewsky, R. (2001). Reciprocal Peer Coaching: a Strategy for Training and Development in Professional Disciplines. Jamison, ACT: Higher Education Research and Development Society of Australasia.

Lave, J., and Wenger, E. (1991). Situated Learning: Legitimate Peripheral Participation. Cambridge: Cambridge University Press.

Lieberman, M. D. (2007). Social cognitive neuroscience: a review of core processes. Annu. Rev. Psychol. 58, 259-289. doi: 10.1146/annurev.psych.58.110405. 085654

Marchetti, I., and Koster, E. (2014). Brain and intersubjectivity: a Hegelian hypothesis on the self-other neurodynamics. Front. Hum. Neurosci. 8:11. doi: 10.3389/fnhum.2014.00011

Melis, A., and Semmann, D. (2010). How is human cooperation different. Philos. Trans. R. Soc. Lond. B Biol. Sci. 365, 2663-2674. doi: 10.1098/rstb.2010.0157

Meltzoff, A. (2005). "Imitation and other minds: the "Like Me" hypothesis" in Perspectives on Imitation: From Neuroscience to Social Science, eds S. Hurley and N. Chater (Cambridge, MA: MIT Press), 55-77.

Menekse, M., and Stump, G. S., Krause, S., and Chi, M. T. H. (2013). Differentiated overt learning activities for effective instruction in an engineering classroom. J. Eng. Educ. 102, 346-374. doi: 10.1002/jee.20021

Mercer, N. (2000). Words and Minds: How We Use Language to Think Together. London: Routledge. 
Molnar-Szakacs, I., and Uddin, L. (2013). Self processing and the Default Mode Network: interactions with the mirror neuron system. Front. Hum. Neurosci. 7:571. doi: 10.3389/fnhum.2013.00571

Montague, P. R., Berns, G. S., Cohen, J. D., McClure, S. M., Pagnoni, G., Dhamala, M., et al. (2002). Hyperscanning: simultaneous fMRI during linked social interactions. Neuroimage 16, 1159-1164. doi: 10.1006/nimg.2002.1150

Murray, E. (2007). The amygdala, reward and emotion. Trends Cogn. Sci. 11, 489497. doi: 10.1016/j.tics.2007.08.013

Mynard, J., and Almarzouqi, I. (2006). Investigating peer-tutoring. ELT J. 60, 13-22. doi: $10.1093 /$ elt/cci077

Nadel, J., and Dumas, G. (2014). The interacting body: intra- and interindividual processes during imitation. J. Cogn. Educ. Psychol. 13, 163-175. doi: 10.1891/ 1945-8959.13.2.163

Newman-Norlund, R. D., van Schie, H. T., van Zuijlen, A. M. J., and Bekkering, H. (2007). The mirror neuron system is more active during complementary compared with imitative action. Nat. Neurosci. 10, 817-818. doi: 10.1038/nn1911

Nicol, D. J., and Macfarlane-Dick, D. (2006). Formative assessment and selfregulated learning: a model and seven principles of good feedback practice. Stud. High. Educ. 31, 199-218. doi: 10.1080/03075070600572090

Organization for Economic Cooperation and Development/Centre for Educational Research and Innovation (OECD/CERI). (2005). Formative Assessment: Improving Learning in Secondary Classrooms. Paris: CERI/OECD.

Organization for Economic Cooperation and Development/Centre for Educational Research and Innovation (OECD/CERI). (2011). Against the Odds: Disadvantage Students Who Succeed at School. Paris: CERI/OECD.

Peterson, P., Wilkenson, L., Spinelli, F., and Swing, S. R. (1984). "Merging the process-product and the sociolinguistic paradigms: research on small group processes" in The Social Context of Instruction: Group Organization and Group Processes, eds L. Peterson, L. Wilkenson, and M. Hallinan (New York: Academic), 535-547.

Pfeiffer, U. J., Schilbach, L., Timmermans, B., Kuzmanovic, B., Georgescu, A. L., Bente, G., et al. (2014). Why we interact: on the functional role of the striatum in the subjective experience of social interaction. Neuroimage 101, 124-137. doi: 10.1016/j.neuroimage.2014.06.061

Pintrich, P. R., and Zusho, A. (2002). "The development of academic selfregulation: the role of cognitive and motivational factors" in Development of Achievement Motivation, eds A. Wigfield and J. S. Eccles (San Diego: Academic Press), 250-284.

Premack, D., and Woodruff, G. (1978). Does the chimpanzee have a theory of mind? Behav. Brain Sci. 4, 515-526. doi: 10.1017/S0140525X00076512

Preston, S. D., and de Waal, F. B. (2002). Empathy: its ultimate and proximate bases. Behav. Brain Sci. 25, 1-20. doi: 10.1017/S0140525X02000018

Putney, L. G., and Broughton, S. H. (2011). Developing collective classroom efficacy: the teacher's role as community organizer. J. Teach. Educ. 62, 93-105. doi: $10.1177 / 0022487110381760$

Qin, P., and Northoff, G. (2011). How is our self related to midline regions and the default-mode network? Neuroimage 57, 1221-1233. doi: 10.1016/ j.neuroimage.2011.05.028

Redcay, E., Dodell-Feder, D., Pearrow, M., Mavros, P., Kleiner, M., Gabrieli, J., et al. (2010). Live face-to-face interaction during fMRI: a new took for social cognitive neuroscience. Neuroimage 50, 1639-1647. doi: 10.1016/ j.neuroimage.2010.01.052

Reyes, J., and Elias, M. J. (2011). Fostering social-emotional resilience among Latino youth. Psychol. Sch. 47, 723-737. doi: 10.1002/pits.20580

Rilling, J. K., Gutman, D. A., Zeh, T. R., Pagnoni, G., Berns, G. S., and Kilts, C. D. (2002). A neural basis for social cooperation. Neuron 35, 395-405. doi: 10.1016/S0896-6273(02)00755-9

Rogoff, B. (1990). Apprenticeship in Thinking. Cognitive Development in Social Context. New York: Oxford University Press.

Rogoff, B. (2003). The Cultural Nature of Human Development. New York: Oxford University Press.

Ruff, C. C., and Fehr, E. (2014). The neurobiology of rewards and values in social decision making. Nat. Rev. Neurosci. 15, 549-562. doi: 10.1038/nrn3776

Ryan, R. M., and Deci, E. L. (2000a). Intrinsic and extrinsic motivation: classic definition and new directions. Contemp. Educ. Psychol. 25, 54-67. doi: 10.1006/ceps.1999.1020

Ryan, R. M., and Deci, E. L. (2000b). Self-determination theory and the facilitation of intrinsic motivation, social development, and well-being. Am. Psychol. 55, 68-78. doi: 10.1037/0003-066X.55.1.68
Sakaiya, S., Shiraito, Y., Kato, J., Ide, H., Okada, K., Takano, K., and Kansaku, K. (2013). Neural correlate of human reciprocity in social interactions. Front. Neurosci. 7:239. doi: 10.3389/fnins.2013.00239

Salamone, J., and Correa, M. (2012). The mysterious motivational functions of mesolimbic dopamine. Neuron 76, 470-485. doi: 10.1016/j.neuron.2012. 10.021

Sandrone, S. (2013). Self through the mirror (neurons) and default mode network: what neuroscientists found and what can still be found there. Front. Hum. Neurosci. 7:383. doi: 10.3389/fnhum.2013.00383

Schilbach, L. (2014). On the relationship of online and offline social cognition. Front. Hum. Neurosci. 8:278. doi: 10.3389/fnhum.2014.00278

Schilbach, L., Wilms, M., Eickhoff, S. B., Romanzetti, S., Tepest, R., Bente, G., et al. (2010). Minds made for sharing: initiating joint attention recruits reward-related neurocircuitry. J. Cogn. Neurosci. 22, 2702-2715. doi: 10.1162/ jocn.2009.21401

Schilbach, L., Wohlschlaeger, A., Kraemer, N., Newen, A., Shah, N., Fink, G., et al. (2006). Being with virtual others: neural correlates of social interaction. Neuropsychologia 44, 718-730. doi: 10.1016/j.neuropsychologia.2005.07.017

Schilbach, L., Timmermans, B., Reddy, V., Costall, A., Bente, G., Schlict, T., et al. (2013). Toward a second-person neuroscience. Behav. Brain Sci. 36, 393-462. doi: 10.1017/S0140525X12000660

Schön, D. (1987). Educating the Reflective Practitioner. San Francisco: Jossey-Bass.

Shea, N., Boldt, A., Bang, D., Yeung, N., Heyes, C., and Frith, C. D. (2014). Suprapersonal cognitive control and metacognition. Trends Cogn. Sci. 18, 186-193. doi: 10.1016/j.tics.2014.01.006

Sivan, E. (1986). Motivation in social constructivist theory. Educ. Psychol. 21, 209233. doi: $10.1207 /$ s15326985ep2103_4

Slavin, R. (1996). Research on cooperative learning and achievement: what we know, what we need to know. Contemp. Educ. Psychol. 21, 43-69. doi: 10.1006/ceps.1996.0004

Sperduti, M., Guionnet, S., Fossati, P., and Nadel, J. (2014). Mirror Neuron System and Mentalizing system connect during online social interaction. Cogn. Process. 15, 307-316. doi: 10.1007/s10339-014-0600-x

Storch, N. (2002). Patterns of interaction in ESL Pair Work. Lang. Learn. 51, 119 158. doi: 10.1111/1467-9922.00179

Supekar, K., Uddin, L., Prater, K., Amin, H., Greicus, M., and Memon, V. (2010). Development of functional and structural connectivity within the default mode network. Neuroimage 52, 290-301. doi: 10.1016/j.neuroimage.2010. 04.009

Tabibnia, G., and Lieberman, M. D. (2007). Fairness and cooperation are rewarding. Ann. N. Y. Acad. Sci. 1118, 90-101. doi: 10.1196/annals.1412.001

Tiknaz, Y., and Sutton, A. (2006). Exploring the role of assessment tasks to promote formative assessment at Key Stage 3 geography: evidence from twelve teachers. Assess. Educ. 13, 327-343. doi: 10.1080/09695940601035502

Timmermans, B., Schilbach, L., Pasquali, A., and Cleeremans, A. (2012). Higher order thoughts in action: consciousness as an unconscious re-description process. Philos. Trans. R. Soc. Lond. B Biol. Sci. 19, 1412-1423. doi: 10.1098/ rstb.2011.0421

Timmermans, B., Schlicht, T., and Schilbach, L. (2013). Social interaction builds the 'we-mode': commenting on Gallotti and Frith. Trends Cogn. Sci. 17, $160-165$.

Topping, K. J. (1996). The effectiveness of peer tutoring in further and higher education: a typology and review of the literature. High. Educ. 32, 321-345. doi: 10.1007/BF00138870

Uddin, L., Iacobani, M., Lange, C., and Keenan, J. (2007). The self and social cognition: the role of cortical midline structures and mirror neurons. Trends Cogn. Sci. 11, 153-157. doi: 10.1016/j.tics.2007.01.001

van der Meer, J. (2011). "Māori and Pasifika students' academic engagement: what can institutions learn from the AUSSE data" in Student Engagement in New Zealand Universities, ed. A. Radloff (Melbourne: Australian Council of Educational Research), 1-85.

van Zundert, M., Sluijsmans, D., and van Merriënboe, J. (2010). Effective peer assessment processes: research findings and future directions. Learn. Instr. 20, 270-279. doi: 10.1016/j.learninstruc.2009.08.004

Vygotsky, L. S. (1978). Mind in Society: The Development of Higher Psychological Processes. Cambridge: Harvard University Press.

Vygotsky, L. S. (1987). "Thinking and speech" in The Collected Works of L. S. Vygotsky, Vol. 1, Problems of General Psychology, eds R. W. Rieber and A. S. Carton (New York and London: Plenum), 39-285. 
Wagner, U., Galli, L., Schott, B., Wold, A., and van der Schalk, J. (2014). Beautiful friendship: social sharing of emotions improves subjective feelings and activates the neural reward circuitry. Soc. Cogn. Affect. Neurosci. doi: 10.1093/scan/nsu121 [Epub ahead of print].

Walker, R. (2010). "Sociocultural issues in motivation" in International Encyclopedia of Education, eds P. Peterson, E. Baker, and B. McGaw (Oxford: Elsevier), 712-717.

Washington, S. D., Gordon, E. M., Brar, J., Warburton, S., Sawyer, A. T., Wolfe, A., et al. (2014). Dysmaturation of the default mode network in autism. Hum. Brain Mapp. 35, 1284-1296. doi: 10.1002/hbm.22252

Waxman, H. C., Padrón, Y. N., Shin, J. Y., and Rivera, H. H. (2008). Closing the achievement gap within reading and mathematics classrooms by fostering Hispanic students' educational resilience. Int. J. Hum. Soc. Sci. 3, 24-34.

White, E. M. (1984). Holisticism. Coll. Compos. Commun. 35, 385-502. doi: $10.2307 / 357792$

Willis, J. (2010). Assessment for learning as a participative pedagogy. Assess. Matters 2, 65-84.

Wood, D. J., Bruner, J. S., and Ross, G. (1976). The role of tutoring in problem solving. J. Child Psychiatry Psychol. 17, 89-100. doi: 10.1111/j.1469-7610.1976. tb00381.x
Yamasue, H., Kuwabara, H., Kawakubo, Y., and Kasai, K. (2009). Oxytocin, sexually dimorphic features of the social brain, and autism. Psychiatry Clin. Neurosci. 63, 129-140. doi: 10.1111/j.1440-1819.2009.01944.x

Conflict of Interest Statement: The authors declare that the research was conducted in the absence of any commercial or financial relationships that could be construed as a potential conflict of interest.

Received: 02 October 2014; paper pending published: 19 November 2014; accepted: 07 January 2015; published online: 10 February 2015.

Citation: Clark I and Dumas G (2015) Toward a neural basis for peer-interaction: what makes peer-learning tick? Front. Psychol. 6:28. doi: 10.3389/fpsyg.2015.00028

This article was submitted to Educational Psychology, a section of the journal Frontiers in Psychology.

Copyright (c) 2015 Clark and Dumas. This is an open-access article distributed under the terms of the Creative Commons Attribution License (CC BY). The use, distribution or reproduction in other forums is permitted, provided the original author(s) or licensor are credited and that the original publication in this journal is cited, in accordance with accepted academic practice. No use, distribution or reproduction is permitted which does not comply with these terms. 